\title{
Reactivity Model as a Tool to Compare the Combustion Process in Aviation Turbine Engines Powered by Synthetic Fuels
}

\author{
Tomasz Białecki *(D), Wojciech Dzięgielewski (D, Mirosław Kowalski ${ }^{D}$ and Andrzej Kulczycki (D) \\ Fuels and Lubricants Division, Air Force Institute of Technology (ITWL), 01-494 Warsaw, Poland; \\ wojciech.dziegielewski@itwl.pl (W.D.); miroslaw.kowalski@itwl.pl (M.K.); andrzej.kulczycki@itwl.pl (A.K.) \\ * Correspondence: tomasz.bialecki@itwl.pl; Tel.: +48-261-851-406
}

\section{check for} updates

Citation: Białecki, T.; Dzięgielewski, W.; Kowalski, M.; Kulczycki, A. Reactivity Model as a Tool to Compare the Combustion Process in Aviation Turbine Engines Powered by Synthetic Fuels. Energies 2021, 14 6302. https://doi.org/10.3390/ en14196302

Academic Editors: Alexandre M. Afonso, Pedro Resende and Mohsen Ayoobi

Received: 29 July 2021

Accepted: 24 September 2021

Published: 2 October 2021

Publisher's Note: MDPI stays neutral with regard to jurisdictional claims in published maps and institutional affiliations.

Copyright: (c) 2021 by the authors. Licensee MDPI, Basel, Switzerland. This article is an open access article distributed under the terms and conditions of the Creative Commons Attribution (CC BY) license (https:// creativecommons.org/licenses/by/ $4.0 /)$.

\begin{abstract}
The paper aims to verify the thesis that the reactivity model, developed in earlier research, can be used to compare the fuels combustion processes in turbine engines, which is important for predicting the behavior of different alternative fuels in combustion process. Synthetic blending components from alcohol to jet and hydroprocessed esters and fatty acids technologies and their blends with conventional jet fuel were used in tests. The undertaken laboratory tests reveal the differences between the properties of the tested fuels. Bench tests were carried out on a test rig with a miniature turbojet engine, according to authorial methodology. For each blend, on selected points of rotational speed the carbon oxide concentration in the exhaust gases was recorded. The obtained results allowed the formulation of empirical power functions describing relations between carbon oxide concentration and fuel mass flow rate. Based on general assumptions, the reactivity model was adopted to compare the combustion processes of the different fuels in turbine engines. The directions of further research on the development of the proposed model were indicated.
\end{abstract}

Keywords: combustion process; reactivity model; synthetic jet fuels; turbine engines

\section{Introduction}

Intensive development of road and air transport leads to increasing air pollution from internal combustion engines. At a global scale, the most important is carbon dioxide $\left(\mathrm{CO}_{2}\right)$ emission, considered a cause of the global warming effect. At a local scale, more important is carbon oxide (CO) emission, unburned hydrocarbons, particulate matter (PM), as well as nitrogen oxides $\left(\mathrm{NO}_{\mathrm{x}}\right)$ emissions.

The majority of countries have declared important the implementation of $\mathrm{CO}_{2}$ emissions reduction programs and the promotion of the use of energy from renewable sources [1]. The fundamental way to achieve the goal is the implementation of biofuels into road, marine and air transport [2-4]. Alternative or synthetic fuels, unlike conventional fossil fuels, are produced from a feedstock other than crude oil. If the used feedstock is biomass, waste, animal fat, biogas, etc. then we define it as biofuels.

Biofuels have been implemented in road transport for about 20 years. The components commonly used in fuels are bioethanol as an automotive gasoline component and fatty acid methyl esters (FAME) as a diesel fuel component. The technologies used to manufacture alternative fuels for aircraft turbine engines have been under development for about 10 years [5]. As of today, the seven synthetic components are approved for aviation turbine engines [6], while it is anticipated that further fuels using alternative feedstocks [7] will be introduced to the market. Regarding the chemical composition, jet fuels containing synthesized hydrocarbons are more similar to conventional fuels than biofuels containing bioethanol and FAME. However, the hydrocarbon composition influences the combustion process, hence the engine operating parameters and composition of exhaust gases [8-10].

Research regarding new components, both for compression-ignition, and aviation turbine engines demands the development of predictive methods, and the assessment of the effect of a fuel chemical composition on the combustion process [11-14]. 


\section{Modelling of the Combustion Process}

The combustion process in the turbine engine is characterized by strong diversification of reaction chains depending on engine operating parameters and the temperature of the combustion chamber [15-21]. Fuel combustion in turbine engines is a complex process. In general, the combustion process can be treated as the linkage of the following processes: fuel atomization after injection to the combustion chamber; vaporization, together with further thermal degradation; a large number of chemical reactions as fuel oxidation occurs [22]. Where the turbine engine is not equipped with injectors but is equipped with evaporator tubes, no fuel atomization takes place.

In the combustion process, there are strong interactions between elemental processes. This brings about difficulties in modelling it. In particular, it is very difficult to mathematically describe the influence of the fuel chemical composition on the combustion process. The chemical composition of the fuels is qualitatively described by the structure of the compounds present in the fuel. The only quantitative data are the concentrations of individual compounds, or more frequently, the concentrations of hydrocarbons i.e., n-paraffins, iso-paraffins, naphthenes, aromatics. The molecules of individual chemical compounds interact with each other, which affects fuels atomization, vaporization, as well as chemical reactions during the combustion process. However, the nature of molecular interactions has not been sufficiently understood. Certain authors [23], for example, describe the creation of molecular clusters by polycyclic aromatic hydrocarbons (PAH), and point to the clusters as the soot source. The molecular cluster is an ordered structure of unique properties, different from the volumetric properties of fuel treated as the liquid. This regards the energy state and ability to transfer energy. Conventional jet fuel does not contain PAH or any synthetic components. However, monoaromatics and other kinds of hydrocarbons can form similar structures that influence the chemical reactions in the combustion process.

The above-mentioned complexity of the chemical composition of fuels, as well as the complexity of individual processes taking place in the combustion chamber, makes modelling of the combustion process difficult $[24,25]$.

Research on the dependence of the combustion process, and as a consequence, engine operating parameters, and exhaust gas composition, is being carried out at different levels, from macroscopic (engine tests) to molecular (tests in laboratory reactors). Currently available models such as SAE [26], and that based on such solvers as Ansys Fluent [27] and Chemkin [28] do not sufficiently take into account the chemical composition and properties of fuels. Indeed, the SAE model requires the assumption that fuel is a single compound consisting of C, H, N, O, S. In contrast, Ansys Fluent and Chemkin take into account thermodynamic data and selected properties of material (fuel), such as neat heat of combustion, viscosity, thermal conductivity, mass diffusivity and thermal diffusion. Moreover, Ansys Fluent provides a description of several fuel combustion mechanisms (including reactions, thermodynamic data, and transport data) that are appropriate for use in combustion simulations of:

- Methane/ethane;

- Propane;

- Hydrogen.

During the combustion process in a turbine engine, the following (chains of) reactions are possible:

$$
\begin{aligned}
\mathrm{C}_{x} \mathrm{H}_{y}+\left(x+\frac{y}{4}\right) \mathrm{O}_{2} & \rightarrow x \mathrm{CO}_{2}+\frac{y}{2} \mathrm{H}_{2} \mathrm{O} \\
\mathrm{C}_{x} \mathrm{H}_{y}+\left(\frac{x}{2}+\frac{y}{4}\right) \mathrm{O}_{2} & \rightarrow x \mathrm{CO}+\frac{y}{2} \mathrm{H}_{2} \mathrm{O} \\
\mathrm{C}_{x} \mathrm{H}_{y}+\frac{1}{4} y \mathrm{O}_{2} & \rightarrow x \mathrm{C}+\frac{1}{2} y \mathrm{H}_{2} \mathrm{O} \\
\mathrm{CO}_{2}+\mathrm{H}_{2} & \rightarrow \mathrm{CO}+\mathrm{H}_{2} \mathrm{O} \\
\mathrm{CO}+\frac{1}{2} \mathrm{O}_{2} & \rightarrow \mathrm{CO}_{2}
\end{aligned}
$$


Reactions (1)-(3) are a summary record of the long chains of reactions. In addition, conventional and synthetic fuels are mostly a mixture of many (even up to 1000) chemical compounds, mainly hydrocarbons. The usefulness of the SAE model and that of the solvers indicated above are limited. The reason for such situation is that in the application of statistical tools to formulate the necessary dependencies with any weaknesses of the statistics:

- The values of the constant parameters of these relationships are determined for a specific set of tested fuels, the values may be incorrect for a new fuel, e.g., synthetic fuel;

- A physical interpretation of statistically determined parameters is not possible.

The use of mathematical models for the combustion process, as currently available $[28,29]$, give dependencies that show significant deviation from experimental data.

When considering the possibility of introducing a new, synthetic fuel, two basic questions should be answered, with regard to a comparison with conventional fuel:

- How will this new fuel change the combustion process in the engine;

- How will this new fuel change the emission of exhaust components.

Consequently, the products formed during combustion $\left(\mathrm{CO}_{2}, \mathrm{CO}\right.$ and $\left.\mathrm{PM}\right)$ are important components of exhaust gases. The concentration of $\mathrm{CO}_{2}, \mathrm{CO}$ and $\mathrm{PM}$ in exhaust gases is used to:

- Assess the influence of the combustion process in turbine engines on air pollution;

- Assess the influence of fuel chemical composition on the combustion process.

The impact of fuel chemical composition on the combustion process can be assessed qualitatively or quantitatively. The quantitative assessment gives a more complete description of this impact, but it needs quantitative data related to the fuel chemical composition and the chemical reactions of fuel combustion. The reactions (1-5) can be described quantitatively by kinetic equations, where the data are the volume of fuel introduced into combustion chamber $\left(m_{f} t\right)$ and concentration of the chosen product of combustion. The kinetic equations make possible formulation of the function describing relationships between the concentration of the products of fuel combustion ([CO] or $\left.\left[\mathrm{CO}_{2}\right]\right)$ and $m_{f}$. Such relationships seem to be more useful in combustion process analysis than the analysis of separate [CO] values for various $m_{f}$ (as usually found in literature).

The reaction rate constants in the kinetic equations of combustion (described by the Arrhenius equation) can be related to the conditions of combustion process-temperature in combustion chamber and chemical structure of the fuel-activation energy. The activation energy has a physical meaning in relation to a single reaction, but in relation to a chain of reactions it is difficult to interpret it, physically. Consequently, it is practically impossible to relate the reaction rate constant quantitatively to the chemical structure of the fuel.

The basic problem is how to describe quantitatively the chemical composition of fuel, when such fuel consists of many compounds (mainly hydrocarbons). The way, proposed in this paper, is by using the reactivity model. The general assumption of this model is that every fuel, even that very complex, can be assigned a $\alpha_{i}$ coefficient that is the ratio of the external forcing causing the combustion process, to the energy response of the system resulting from chemical reactions. The coefficient $\alpha_{i}$ can be treated as the quantitative measure of fuels structure related to the given process. The reactivity of the tested product (fuel, lubricating oil, etc.) is understood as its ability to undergo chemical reactions caused by external mechanical (tribology) or thermal (combustion of fuel) influences that affect the course of the operational process, i.e., lubrication or engine operation.

The mathematical assumptions of the reactivity model were previously developed for reactions initiated by heat and mechanical forces that stimulated tribological processes [30].

The assumptions of the reactivity model are based on the relation of two functions: $f(z)$ and $\phi(z)$. The fundamental relationship for this model is the following:

$$
\alpha_{i}=\frac{f(z)-f_{0}(z)}{\phi(z)-\phi_{0}(z)} \cdot \frac{d \phi(z)}{d f(z)}
$$


Here, the combustion process is described by two functions of the same variable $z$ (chosen independent parameter characterizing the combustion process, e.g., $m_{f}$ ), where $f(z)$ and $\phi(z)$ are related to the tested fuel, and $f_{o}(z)$ and $\phi_{o}(z)$ are related to the reference fuel.

This general relationship should be adapted to the process that is the subject of this investigation. In case of the investigations described in this paper, the observed process is the fuel combustion in the turbine jet engine. The parameter that provides quantitative information about the influence of chemical structure of the tested fuel on the combustion process is the reactivity coefficient $\alpha_{i}$, and:

$$
\begin{gathered}
f(z)=L \\
\phi(z)=A(z)
\end{gathered}
$$

where $z$ is the parameter chosen as the only variable and $A(z)$ is a function describing the reactions initiated by the energy supplied from environment to the system $(L)$. Herein, $A(z)$ can be expressed as the function of constant rate of reaction or the concentration of the products of the reaction-according to the problem being solved.

Preliminary research has shown that this model can be useful for the analysis of various processes. This allows us to focus on one chosen component of a very complex blend, and describe this component influence on a complex process such as the fuel combustion in an engine [21]. The investigation of the influence of synthetic components on the combustion process in turbine engines should be conducted in a relative manner. It is assumed that the concentration of carbon monoxide in the exhaust gases is an indicator of the similarity of the combustion process of synthetic fuel to the reference conventional fuel.

During preliminary investigations on catalysis and tribocatalysis [30], it was found that instead of the kinetic equation (kinetic model), the dynamic reactivity model can be used. The reactivity model, developed by these authors for catalytic (including tribochemical) processes modelling, can be more useful than models developed up to now in modelling the influence of fuel chemical composition and properties on the combustion process.

The paper aims to verify the thesis that the reactivity model, developed in earlier research, can be used to compare fuels combustion processes in turbine engines. Taking into account the usefulness of models for predicting the influence of new components or additives added to the fuel on combustion process, and the needed analysis of the influence of new fuel components on the mechanism of the combustion process, a new model is proposed. Preliminary tests have shown that this model can be useful for describing the mechanisms of various processes analysis which allows us to focus on the one chosen compound or component in a very complex mixture, as well as to describe this chosen component influence on a complex process such as the fuel combustion in an engine. In this paper, this model was chosen to verify the possibility of its application for the description of combustion process. The assumptions of the proposed, new mathematical model of fuel combustion are based on a model developed previously for reactions initiated by heat and mechanical forces.

\section{Materials and Methods}

\subsection{Tested Fuels}

Fossil jet fuel Jet A-1 and its blends with synthetic blending components from alcohol to jet (ATJ) and hydroprocessed esters and fatty acids (HEFA), approved by ASTM D7566, were used in the tests. The synthetic components from ATJ and HEFA technologies consist of synthetic hydrocarbons. The above-mentioned tested fuels were designated in the paper as:

- $\quad$ Conventional jet fuel-Jet 1 and Jet 2;

- $\quad$ Blend of Jet 1 with $5 \%$ of synthetic component HEFA-5HEFA;

- $\quad$ Blend of Jet 1 with $20 \%$ of synthetic component HEFA-20HEFA;

- Blend of Jet 1 with $30 \%$ of synthetic component HEFA-30HEFA; 
- $\quad$ Blend of Jet 2 with $50 \%$ of synthetic component ATJ—50ATJ;

- Synthetic blending component from ATJ technology-ATJ.

The properties of the tested fuels are shown in Table 1.

Table 1. Properties of tested fuels.

\begin{tabular}{|c|c|c|c|c|c|c|c|}
\hline Property & Jet 1 & 5HEFA & 20HEFA & $\begin{array}{l}\text { Tested Fuels } \\
\text { 30HEFA }\end{array}$ & Jet 2 & $50 \mathrm{ATJ}$ & ATJ \\
\hline Density at $15^{\circ} \mathrm{C}, \mathrm{kg} / \mathrm{m}^{3}$ & 793.1 & 790.5 & 787.0 & 782.7 & 793.0 & 776.1 & 758.6 \\
\hline Viscosity at $-20^{\circ} \mathrm{C}, \mathrm{mm}^{2} / \mathrm{s}$ & 3.069 & 3.288 & 3.403 & 3.470 & 3.062 & 3.654 & 4.740 \\
\hline Net heat of combustion, $\mathrm{MJ} / \mathrm{kg}$ & 43.312 & 43.335 & 43.484 & 43.570 & 43.231 & 43.599 & 44.027 \\
\hline Aromatics, $\%(V / V)$ & 15.1 & 14.3 & 12.1 & 10.6 & 17.3 & 8.8 & 0 \\
\hline $\begin{array}{c}\text { Distillation: } \\
10 \% \text { Recovery, }{ }^{\circ} \mathrm{C} \\
50 \% \text { Recovery, }{ }^{\circ} \mathrm{C} \\
90 \% \text { Recovery, }{ }^{\circ} \mathrm{C} \\
\text { End point, }{ }^{\circ} \mathrm{C}\end{array}$ & $\begin{array}{l}166.1 \\
183.4 \\
208.1 \\
231.2\end{array}$ & $\begin{array}{l}170.6 \\
186.8 \\
214.1 \\
2394\end{array}$ & $\begin{array}{l}169.9 \\
188.3 \\
220.2 \\
246.7\end{array}$ & $\begin{array}{l}169.0 \\
189.3 \\
224.7 \\
249.5\end{array}$ & $\begin{array}{l}166.1 \\
183.4 \\
208.1 \\
231.2\end{array}$ & $\begin{array}{l}170.5 \\
182.1 \\
209.0 \\
246.2\end{array}$ & $\begin{array}{l}175.5 \\
181.2 \\
210.3 \\
262.7\end{array}$ \\
\hline
\end{tabular}

All selected laboratory properties affect the combustion process. The net heat of combustion determines the economy of the engine and its characteristics, and, along with the density, it is taken into account in flight range calculations. Viscosity affects the injection process and the fuel stream range and its atomization into the combustion chamber. Distillation affects the rate of fuel evaporation, while aromas tend to incomplete combustion.

The addition of synthetic component to conventional fuel brings about changes in several physicochemical properties. When HEFA and ATJ are added, the density decreases and the viscosity and heat of combustion increases. These changes are so significant that they can differentiate the combustion process. The differences in the composition of tested fuels are typified by the example of the content of aromas, the value of which is proportional to their blend in the tested fuel. The smallest differences occur in the course of distillation, although in this case the influence of the composition on the distillation of the blend is also noticeable, especially in end point.

\subsection{Bench Test}

The analysis of the combustion process was conducted using a laboratory test rig with a miniature turbojet engine-MiniJETRig (Figure 1). The test rig was constructed for the research of alternative fuels combustion processes [31-33], and it is also used in other development works $[9,34,35]$. MiniJETRig consists of:

- A miniature turbojet engine-single spool with a single stage radial compressor and annular combustion chamber. It works in the range of 33,000-120,000 rpm and generates a maximum thrust of $140 \mathrm{~N}$;

- An exhaust analyzer with an electrochemical sensor in the range of 0-2000 (ppm) for $\mathrm{CO}$ measurement and an infrared sensor in the range of $0-25(\%)$ for $\mathrm{CO}_{2}$ measurement. The accuracy of the device measurements is $5 \%$ of the measured value;

- Control system with data acquisition based on the measurement cards;

- During the undertaken tests, measurements were made with the following sensors:

- Optical rotational speed measurement sensor-SFH 203 FA photodiode, measuring range: $0-120,000 \mathrm{rpm}$;

- Fuel mass flow rate measurement system (thermodynamic flow measurement) Digmes FHKSC flow meter, measuring range: $0.033-2 \mathrm{~L} / \mathrm{min}$, accuracy $\pm 2 \%$ of the measured value. 


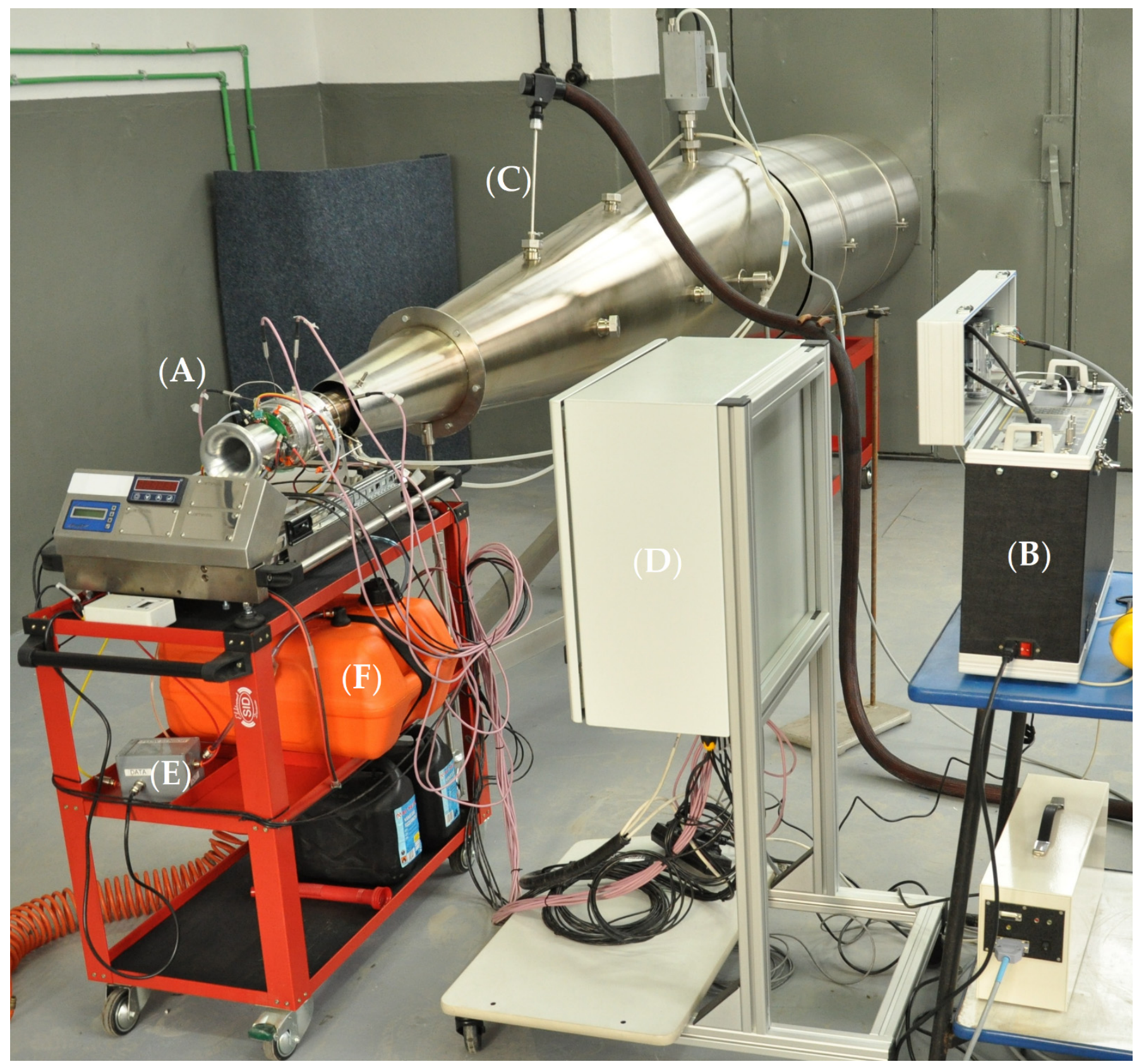

Figure 1. MiniJETRig: (A) miniature turbojet engine, (B) exhaust analyzer, (C) exhaust gas sample probe, (D) block of measurement cards, (E) flow meter, (F) fuel tank.

The tests were conducted at the range of 45,000-120,000 rpm. Due to the stabilization of the measured parameters, the results from the last $20 \mathrm{~s}$ of the engine run on a selected operating mode (100 individual measurements) were averaged and assumed as the measurement result. The fuel mass flow rate was regulated to obtain the expected value of engine rotational speed.

$\mathrm{CO}$ concentration in exhaust gases was assumed as a similarity criterion of the combustion process for different fuels. The $\mathrm{CO}$ formation during the combustion process in turbine engines can be the result of the low local concentration of $\mathrm{O}_{2}$ in the combustion chamber or $\mathrm{CO}$ can be treated as intermediate product in hydrocarbons oxidation to $\mathrm{CO}_{2}$. However, the results of $\mathrm{CO}$ and $\mathrm{CO}_{2}$ concentration during the combustion of Jet A-1 fuel in turbine engines are similar to the change of the products concentration of follow-up reactions. This suggests that $\mathrm{CO}$ can play the role of being an intermediate product (Figure 1). 
Figure 2 shows that at low rotational speeds (idle), the mechanism of the combustion process expressed by $\mathrm{CO}$ and $\mathrm{CO}_{2}$ concentrations is different than at higher rotational speeds (cruise or take-off). For this reason, to develop the reactivity model, only bench test results from 70,000 rpm to $111,000 \mathrm{rpm}$ were analyzed. In the presented graphs, the vertical error bars correspond to the combined standard uncertainty, obtained by combining the individual standard uncertainties (Type A and B).

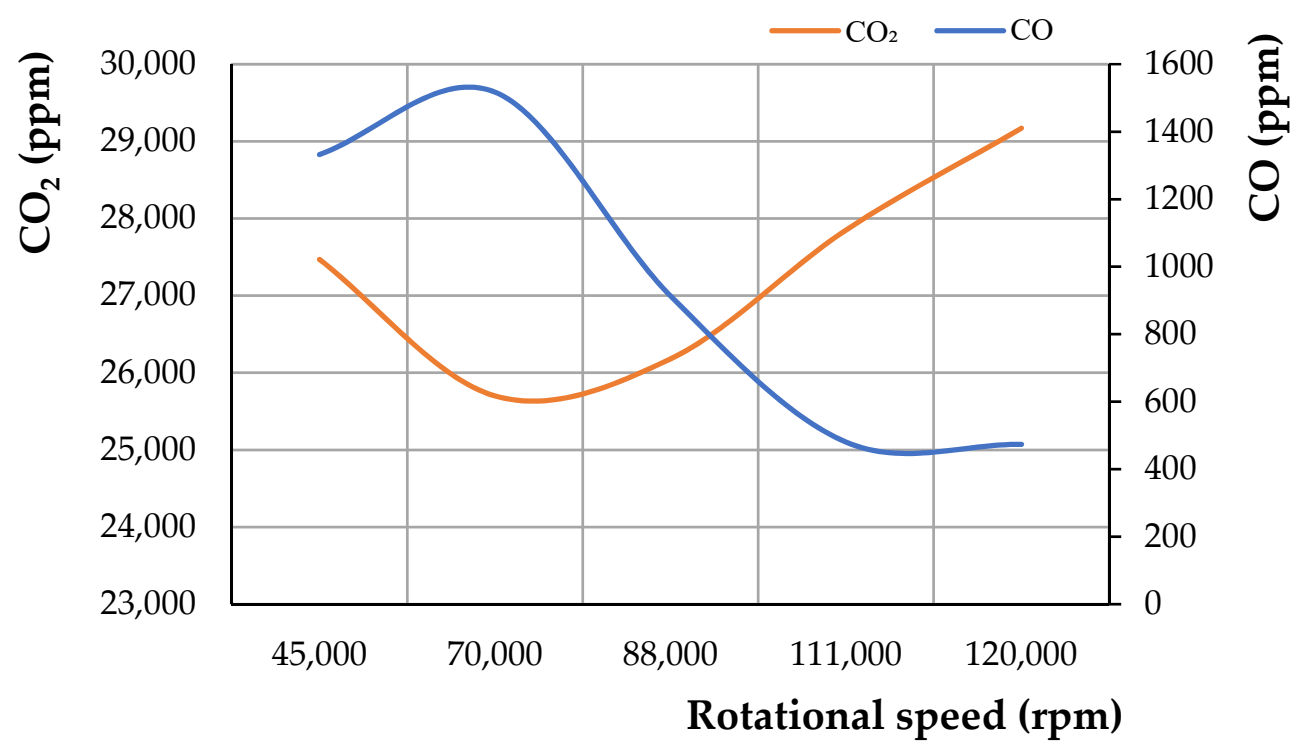

Figure 2. Relationship between $\mathrm{CO}$ and $\mathrm{CO}_{2}$ concentrations in exhaust gases emitted by the miniature jet engine.

\section{Results}

\subsection{Application of the Reactivity Model to the Assessment of the Combustion Process}

The results of the engine tests of fuels containing synthetic components are shown in Figure 3 and the functions describing trend lines are shown in Table 2. The relationship between $\mathrm{CO}$ concentration in exhaust gases and fuel mass flow rate were discovered to be power functions.

Table 2. The power functions describing relationships between $\mathrm{CO}$ concentration in exhaust gases and fuel mass flow rate.

\begin{tabular}{ccc}
\hline Fuel & $\begin{array}{c}\text { Function (from the Trend Line) } \\
\mathbf{C O}=\mathbf{a} m_{f}^{\mathbf{n}}\end{array}$ & $\begin{array}{c}\mathbf{R}^{\mathbf{2}} \\
\text { Coefficient of Determination }\end{array}$ \\
\hline Jet 1 & $\mathrm{CO}=2812 m_{f}^{-1184}$ & 0.90 \\
5HEFA & $\mathrm{CO}=2764 m_{f}^{-1159}$ & 0.93 \\
20HEFA & $\mathrm{CO}=2761 m_{f}^{-1107}$ & 0.94 \\
30HEFA & $\mathrm{CO}=2601 m_{f}^{-1056}$ & 0.93 \\
Jet 2 & $\mathrm{CO}=2698 m_{f}^{-1073}$ & 0.92 \\
50ATJ & $\mathrm{CO}=2899 m_{f}^{-1080}$ & 0.93 \\
ATJ & $\mathrm{CO}=3022 m_{f}^{-1036}$ & 0.94 \\
\hline
\end{tabular}

The above data shows that each tested fuel takes on individual values of the $a$ and $n$ parameters. Using one function defined for a wide range of engine operation parameters, the independent variable $m_{f}$ was found to be connected with CO concentration (the selected parameter describing the combustion process). The reactivity model allows us to interpret physically / chemically, the $a$ and $n$ parameters. Other known models are based on statistical dependences with several consequences. However, the statistically obtained parameters cannot be interpreted physically/chemically. 


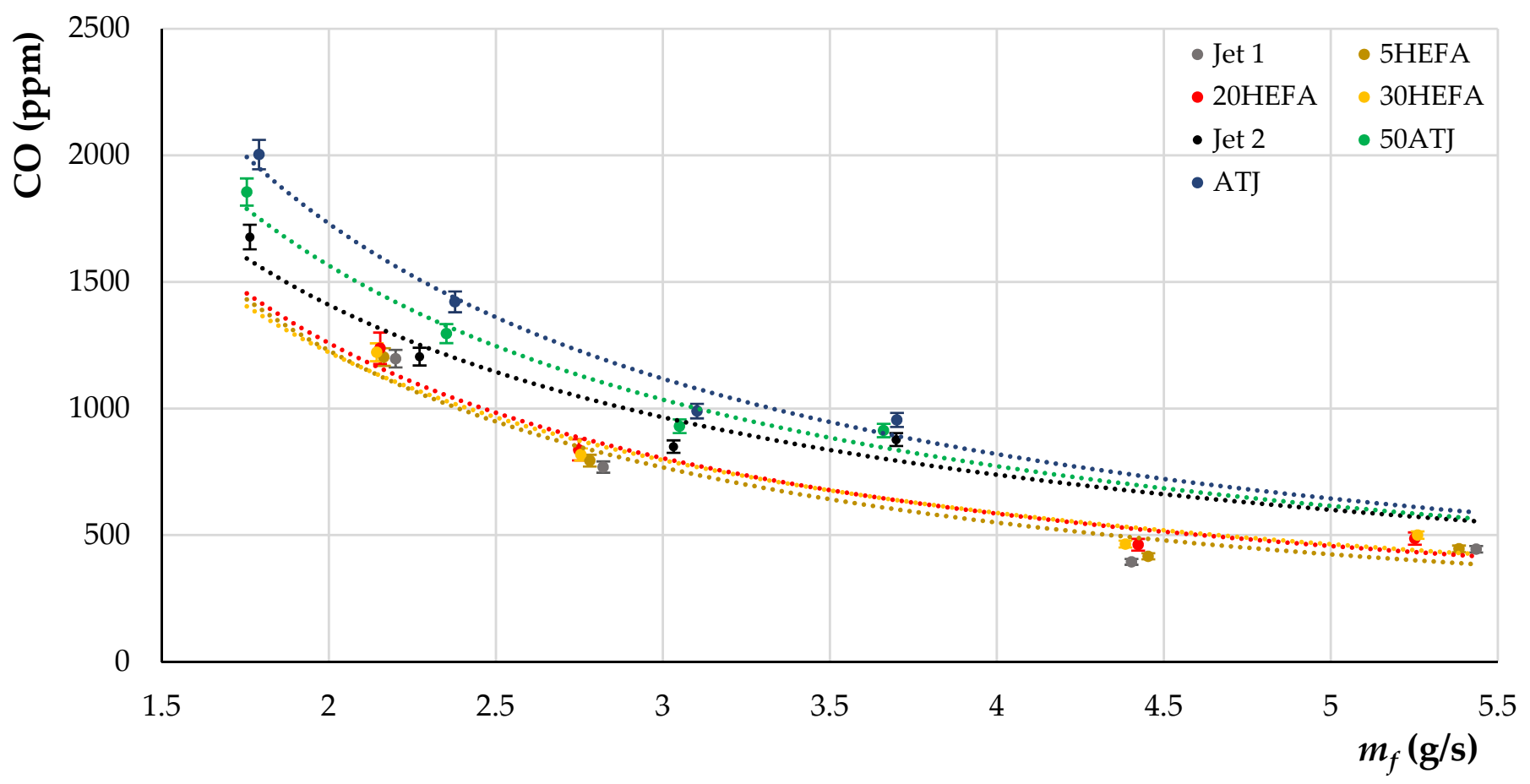

Figure 3. The relationship between $\mathrm{CO}$ concentration and fuel mass flow rate.

Figures 4 and 5 reveal the impact of components concentration in the blends with Jet A- 1 fuel on the $a$ and $n$ parameters. Herein, the $a$ and $n$ parameters were found to change proportionally to the concentration of the synthetic component in the fuel, however, the trend of changes for the HEFA component is opposite to that observed for ATJ. Such differences in trends may be a consequence of different reaction mechanisms during combustion.

Tested fuel

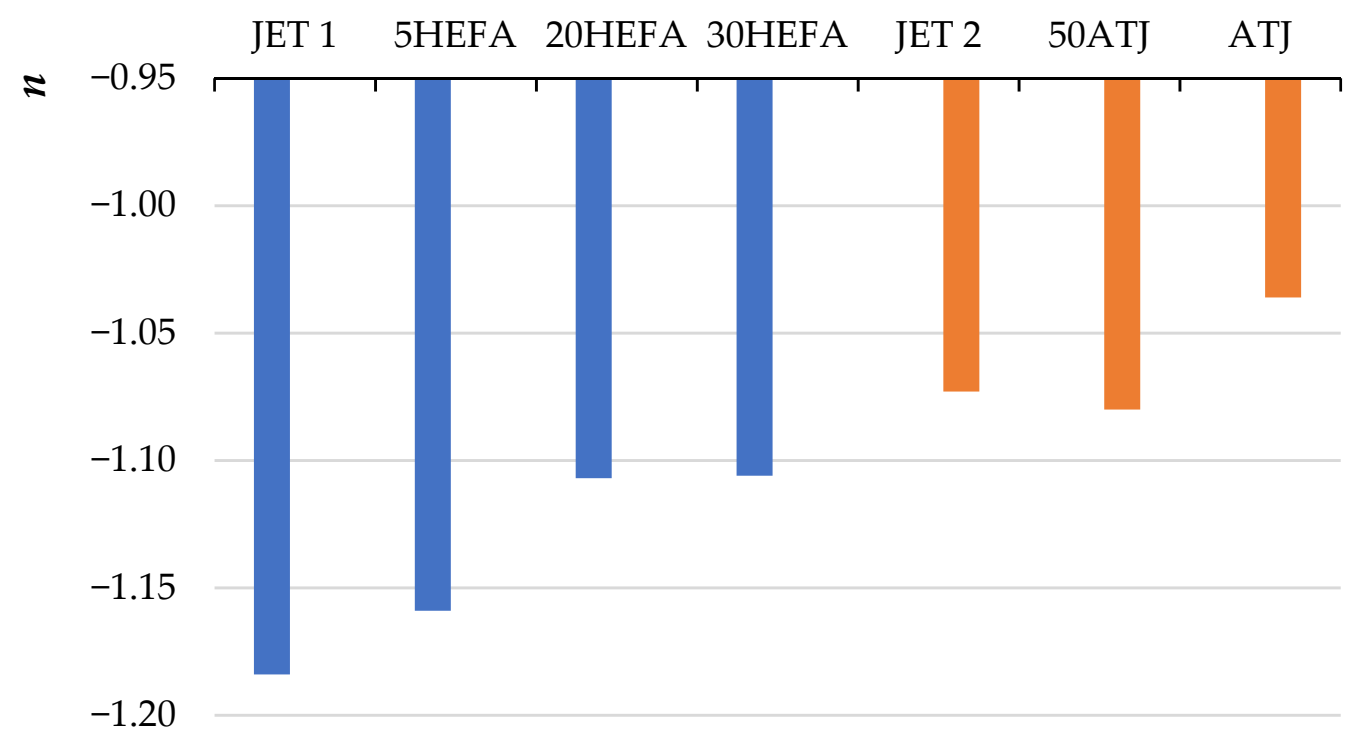

Figure 4. The influence of concentration of HEFA component in blend with Jet A-1 on the $n$ parameter. 


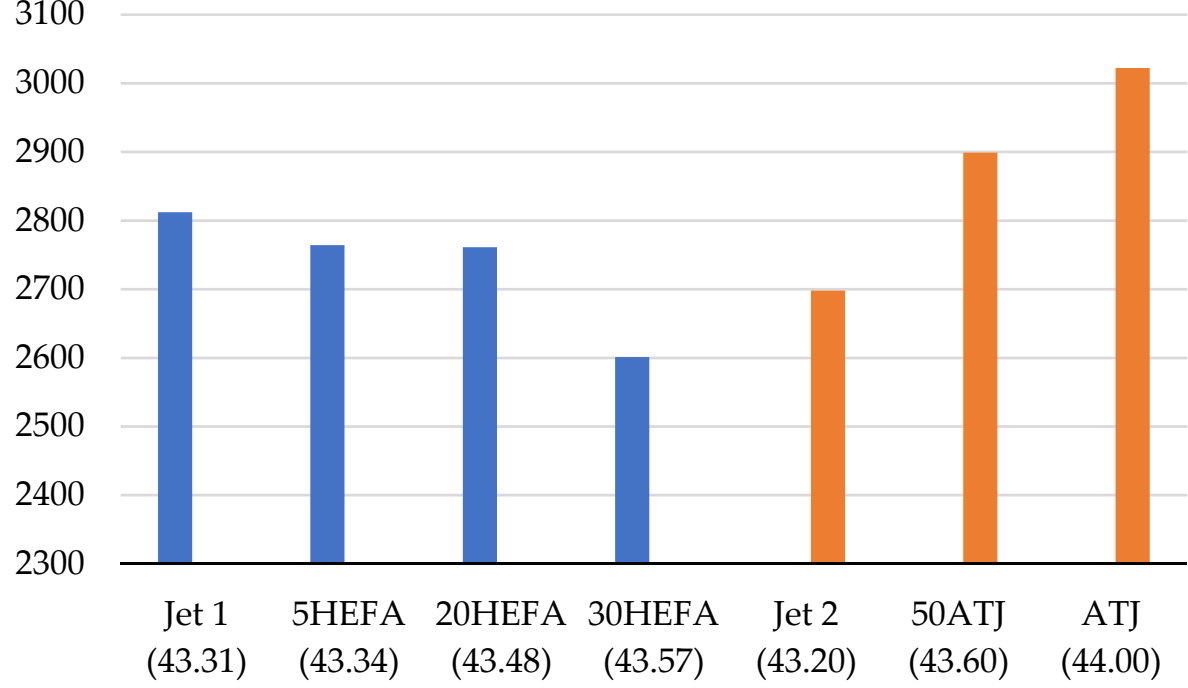

$(43.31)$

$(43.34)$

(43.48)

(43.57)

(43.20)

$(43.60)$

(44.00)

Tested fuel

Figure 5. The influence of concentration of HEFA component in blend with Jet A-1 on the $a$ parameter (net heat of combustion $[\mathrm{MJ} / \mathrm{kg}]$ in brackets).

It should be noted that HEFA consists of a variety of paraffinic and isoparaffinic hydrocarbons, ATJ is a mixture of isoparaffins, while Jet A-1 fuels contain hundreds of paraffinic, isoparaffinic, olefinic, naphthenic and aromatic hydrocarbons.

\subsection{The Use of the Reactivity Model in the Analysis of the Combustion Process-Theoretical Approach}

Based on (6), the overall reactivity model was adapted to develop a combustion model. Usually, the combustion process is described by emission of products such as $\mathrm{CO}_{2}, \mathrm{CO}$, unburned hydrocarbons, etc. In this study the concentration of carbon monoxide in the exhaust gases is treated as an indicator of the similarity of the combustion process of synthetic fuel to the fossil fuel. Moreover, the constant rate of fuel combustion to $\mathrm{CO}_{2}$ in the range of subsequent reactions formation is treated as weakly dependent on the chemical composition of the fuel. For this reason, the influence of fuel chemical composition on $\mathrm{CO}_{2}$ formation was not analyzed. Consequently, kinetic equations that describe $\mathrm{CO}$ creation during the combustion were applied in the reactivity model (6).

In the case wherein the reactivity model will describe only the part of energy generated by the system that is connected with Reaction (2)—oxidation of the fuel hydrocarbons to the $\mathrm{CO}$ and $\mathrm{H}_{2} \mathrm{O}$ \{dependence (6)\}, this should be expressed as:

$$
\left(L_{C O}-L_{0}\right)=\alpha_{i} A[C O]
$$

The reactivity model describes the open system as it is shown in Figure 6.

The combustion process can be treated as consisting of:

- $\quad$ Parallel Reactions (1) and (2);

- Follow-up Reactions (2) and (5);

- The kinetic equations were formulated for both above cases. It was assumed that:

- The fuel is introduced once into the combustion chamber in the amount of $\left[C_{x} H_{y}\right]_{0}=m_{f} t$;

- The order of Reactions (1) and (2) in relation to the tested fuels $\left[C_{x} H_{y}\right]$ is $n$;

- Reaction (5) is of the first order. 


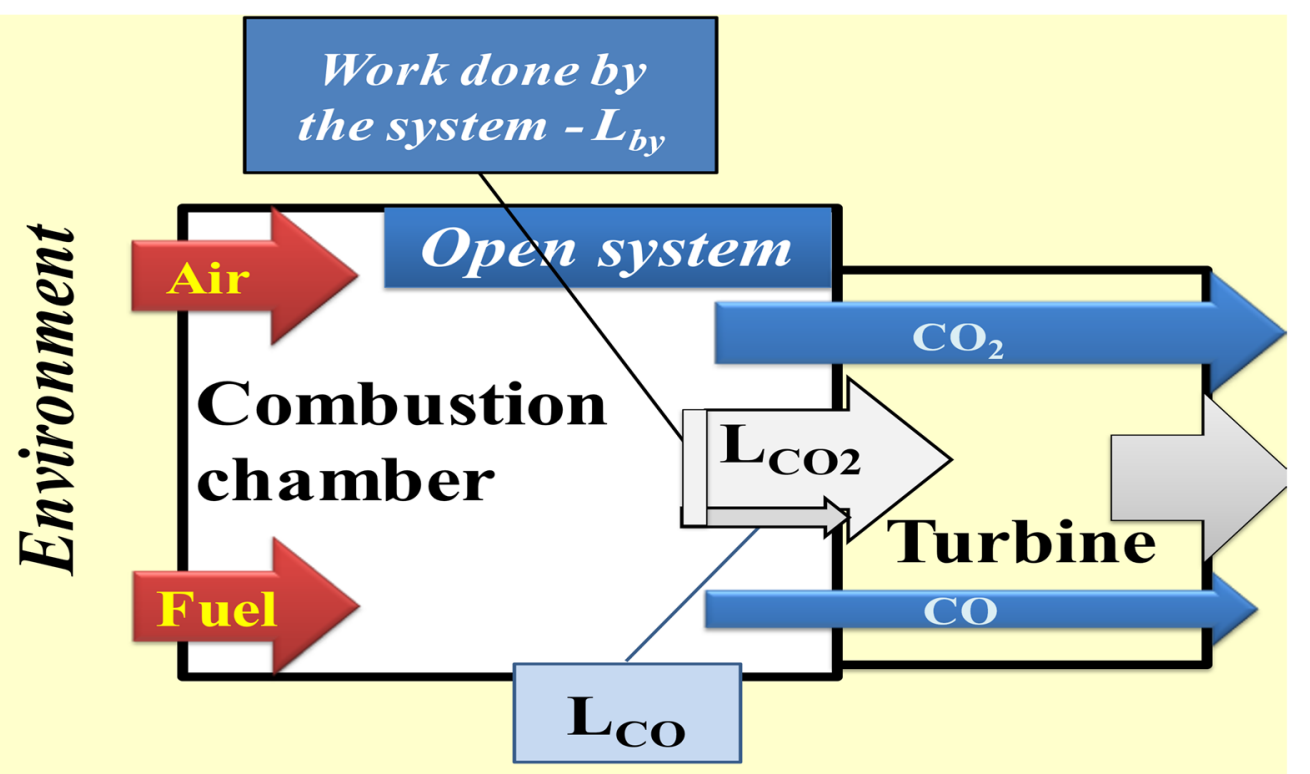

Figure 6. The application of the reactivity model in turbine engine combustion.

The following kinetic equations have been formulated:

1. In the case of the parallel Reactions (1) and (2):

$$
\frac{d\left[C_{x} H_{y}\right]}{d t}=c_{2} k_{\mathrm{CO}}\left[C_{x} H_{y}\right]^{n_{p}}+c_{1} k_{\mathrm{CO} 2}\left[C_{x} H_{y}\right]^{n_{p}}
$$

After integration of Equation (10):

$$
\begin{gathered}
{\left[C_{x} H_{y}\right]^{-n_{p}+1}=\left[C_{x} H_{y}\right]_{0}^{-n_{p}+1}-(-n p+1)\left(c_{2} k_{\mathrm{CO}}+c_{1} k_{\mathrm{CO} 2}\right) t} \\
{\left[C_{x} H_{y}\right]=\left\{\left[C_{x} H_{y}\right]_{0}{ }^{-n_{p}+1}-\left(-n_{p}+1\right)\left(c_{2} k_{\mathrm{CO}}+c_{1} k_{\mathrm{CO} 2}\right) t\right\}^{\frac{1}{-n_{p}+1}}} \\
{\left[C_{x} H_{y}\right]=\left\{\left(m_{f} t\right)^{-n_{p}+1}-\left(-n_{p}+1\right)\left(c_{2} k_{\mathrm{CO}}+c_{1} k_{\mathrm{CO} 2}\right) t\right\}^{\frac{1}{-n_{p}+1}}} \\
\frac{d[\mathrm{CO}]}{d t}=c_{2} k_{\mathrm{CO}}\left[C_{x} H_{y}\right]^{n_{p}} \\
{[\mathrm{CO}]=c_{2} k_{\mathrm{CO}}\left[C_{x} H_{y}\right]^{n_{p}} t} \\
{[\mathrm{CO}]=c_{2} k_{\mathrm{CO}} t\left\{\left[C_{x} H_{y}\right]_{0}^{-n_{p}+1}+\left(-n_{p}+1\right)\left(c_{2} k_{\mathrm{CO}}+c_{1} k_{\mathrm{CO} 2}\right) t\right\}^{\frac{n_{p}}{-n_{p}+1}}} \\
\left.[\mathrm{CO}]=c_{2} k_{\mathrm{CO}} t\left(m_{f} t\right)^{-n_{p}+1}+\left(-n_{p}+1\right)\left(c_{2} k_{\mathrm{CO}}+c_{1} k_{\mathrm{CO} 2}\right) t\right\}^{\frac{n_{p}}{-n_{p}+1}}
\end{gathered}
$$

Using Pascal's triangle, Equation (17) can be shown as follows:

$$
[\mathrm{CO}]=c_{2} k_{\mathrm{CO}} t\left(m_{f} t\right)^{n_{p}}+A_{0}-\left\{\left(-n_{p}+1\right)\left(c_{2} k_{\mathrm{CO}}+c_{1} k_{\mathrm{CO} 2}\right) t\right\}^{\frac{n_{p}}{-n_{p}+1}}
$$

In addition, Equation (16) can be expressed as:

$$
[\mathrm{CO}]=c_{2} k_{\mathrm{CO}}\left(m_{f} t\right)^{n_{p}}
$$

in case the $A_{0}-\left\{\left(-n_{p}+1\right)\left(c_{2} k_{\mathrm{CO}}+c_{1} k_{\mathrm{CO} 2}\right) t\right\}^{\frac{n_{p}}{-n_{p}+1}}$ is small, then e $c_{2} k_{\mathrm{CO}}=a$ and $n_{p}=n$. 
2. In the case of the follow-up Reactions (2) and (5):

$$
\frac{d[\mathrm{CO}]}{d t}=c_{2} k_{\mathrm{CO}}\left[\mathrm{C}_{x} \mathrm{H}_{y}\right]^{n_{p}}-c_{5} k_{\mathrm{CO} 2}[\mathrm{CO}]
$$

Assuming that $\left[\mathrm{C}_{x} \mathrm{H}_{y}\right]$ after a relatively short, fixed time $\mathrm{t}$ is constant, the integration in the range from 0 to $[\mathrm{CO}]$ leads to the following dependence:

$$
\begin{gathered}
\frac{[\mathrm{CO}]}{c_{2} k_{\mathrm{CO}}\left[\mathrm{C}_{x} \mathrm{H}_{y}\right]^{n_{p}}}-c_{5} k_{\mathrm{CO} 2}[\mathrm{CO}]=t \\
c_{2} k_{\mathrm{CO}}\left[\mathrm{C}_{x} \mathrm{H}_{y}\right]^{n_{p}}-c_{5} k_{\mathrm{CO} 2}[\mathrm{CO}]=\frac{1}{t}[\mathrm{CO}] \\
{[\mathrm{CO}]=\frac{c_{2} k_{\mathrm{CO}}\left[C_{x} H_{y}\right]^{n_{p}}}{c_{5} k_{\mathrm{CO} 2}+\frac{1}{t}}}
\end{gathered}
$$

Here, $\left[C_{x} H_{y}\right]$ was determined as follows:

$$
-\frac{d\left[C_{x} H_{y}\right]}{d t}=c_{2} k_{C O}\left[C_{x} H_{y}\right]^{n_{p}}
$$

After integration in the range from $\left[\mathrm{C}_{x} \mathrm{H}_{y}\right]_{0}$ to $\left[\mathrm{C}_{x} \mathrm{H}_{y}\right]$ the following equation was obtained:

$$
\left[C_{x} H_{y}\right]=\left\{\left[C_{x} H_{y}\right]_{0}^{-n_{p}+1}-\left(-n_{p}+1\right)\left(c_{5} k_{\mathrm{CO} 2} t\right)\right\}^{\frac{1}{-n_{p}+1}}
$$

Using Pascal's triangle, $\left[\mathrm{C}_{x} H_{y}\right]$ can be expressed as:

$$
\left[C_{x} H_{y}\right]=\left\{\left[C_{x} H_{y}\right]_{0}+B_{0}-\left(-n_{p}+1\right)\left(c_{5} k_{\mathrm{CO} 2} t\right)\right\}^{\frac{1}{-n_{p}+1}}
$$

By introducing Equation (26) to Equation (23) and substituting $\left[C_{x} H_{y}\right]$ by $m_{f} t$ the following equation was obtained:

$$
[\mathrm{CO}]=\frac{c_{2} k_{\mathrm{CO}}}{c_{5} k_{\mathrm{CO} 2}+\frac{1}{t}}\left[C_{x} H_{y}\right]_{0}^{n_{p}}+B_{0}-\left\{\left(-n_{p}+1\right)\left(c_{5} k_{\mathrm{CO} 2} t\right)\right\}^{\frac{n_{p}}{n_{p}+1}}
$$

Equation (27) can thus be expressed as:

$$
[\mathrm{CO}]=\frac{c_{2} k_{\mathrm{CO}}}{c_{5} k_{\mathrm{CO} 2}+\frac{1}{t}}\left(m_{f} t\right)^{n_{p}}
$$

in case the $B_{0}-\left\{\left(-n_{p}+1\right)\left(c_{5} k_{\mathrm{CO} 2} t\right)\right\}^{\frac{n_{p}}{-n_{p+1}}}$ is small, than $\frac{c_{2} k_{\mathrm{CO}}}{c_{5} k_{\mathrm{CO} 2}+\frac{1}{t}}=a$ and $n_{p}=n$.

Both obtained Equations (19) and (28) are similar to these obtained experimentally as the trend lines.

It is difficult to determine the values of the reactions rate constant $\left(k_{\mathrm{CO}}\right.$ and $\left.k_{\mathrm{CO} 2}\right)$. Consequently, it is difficult to link their values with the properties of the fuel that may be a bridge to the chemical structure of the combusted product. It is proposed to use the reactivity model, represented by Equation (9), to relate the value of $k_{C O}$ to the physicochemical properties of the tested fuels (a mixture of several hundred hydrocarbons). Assuming that $L_{C O}$ can be expressed as a part of total energy released in the combustion process $L_{C O}=g\left(Q_{n} m_{f} t\right)$, Equation (9) can be formulated as follows:

$$
\begin{gathered}
z=m_{f} \\
f(z)=L_{C O}=g\left(Q_{n} m_{f} t\right) \\
\phi(z)=A[C O]=A c_{2} k_{C O} m_{f}{ }^{-n_{p}+1}
\end{gathered}
$$




$$
f_{1}\left(Q_{n} m_{f} t\right)=A \alpha_{i}[C O]+L_{0}
$$

As a result, Equation (31) can be expressed as:

$$
[C O]=\frac{\left\{f_{1}\left(Q_{n} m_{f} t\right)-L_{0}\right\}}{A \alpha_{i}}
$$

In both assumed cases (parallel and follow-up reactions), $\mathrm{CO}$ concentration in exhaust gases should be linear functions of the net heat of combustion $\left(Q_{n}\right)$ of the tested fuels. Hence, the $a$ parameter: $c_{2} k_{\mathrm{CO}}$ in Equation (19) and $\left(\frac{c_{2} k_{\mathrm{CO}}}{c_{5} k_{\mathrm{CO} 2}+\frac{1}{t}}\right)$ in Equation (28) should depend on the coefficient $\alpha_{i}$, the values of which should be different for compositions of jet fuel and different kinds of synthetic components and be similar values for the compositions of jet fuel and the same kind of synthetic components. The $a$ parameter is the product of parameters, the values of which are fixed for a given fuel, including $\alpha_{i}$-coefficient of fuels reactivity related to its combustion. Moreover, in the case where the influence of $m_{f}$ on [CO] is assessed, the ratio of $Q_{n} / \alpha_{i}$ should be a constant value for different blends.

As shown in Figure 4, in the case of fuels containing HEFA synthetic component, the value of the $a$ parameter decreases when $Q_{n}$ increases. In the case of fuels containing ATJ synthetic component, the value of the $a$ parameter increases with the $Q_{n}$ increase. Both synthetic components increase the net heat of combustion proportionally to their concentration in the blend (Figure 7). As the outcome of solving Equations (19) and (28) are related to the data shown on Figures 6 and 7 , this suggests that the mechanism of the influence of synthetic components on the combustion process is different in the case of blends consisting of HEFA and in the case of blends consisting of ATJ.

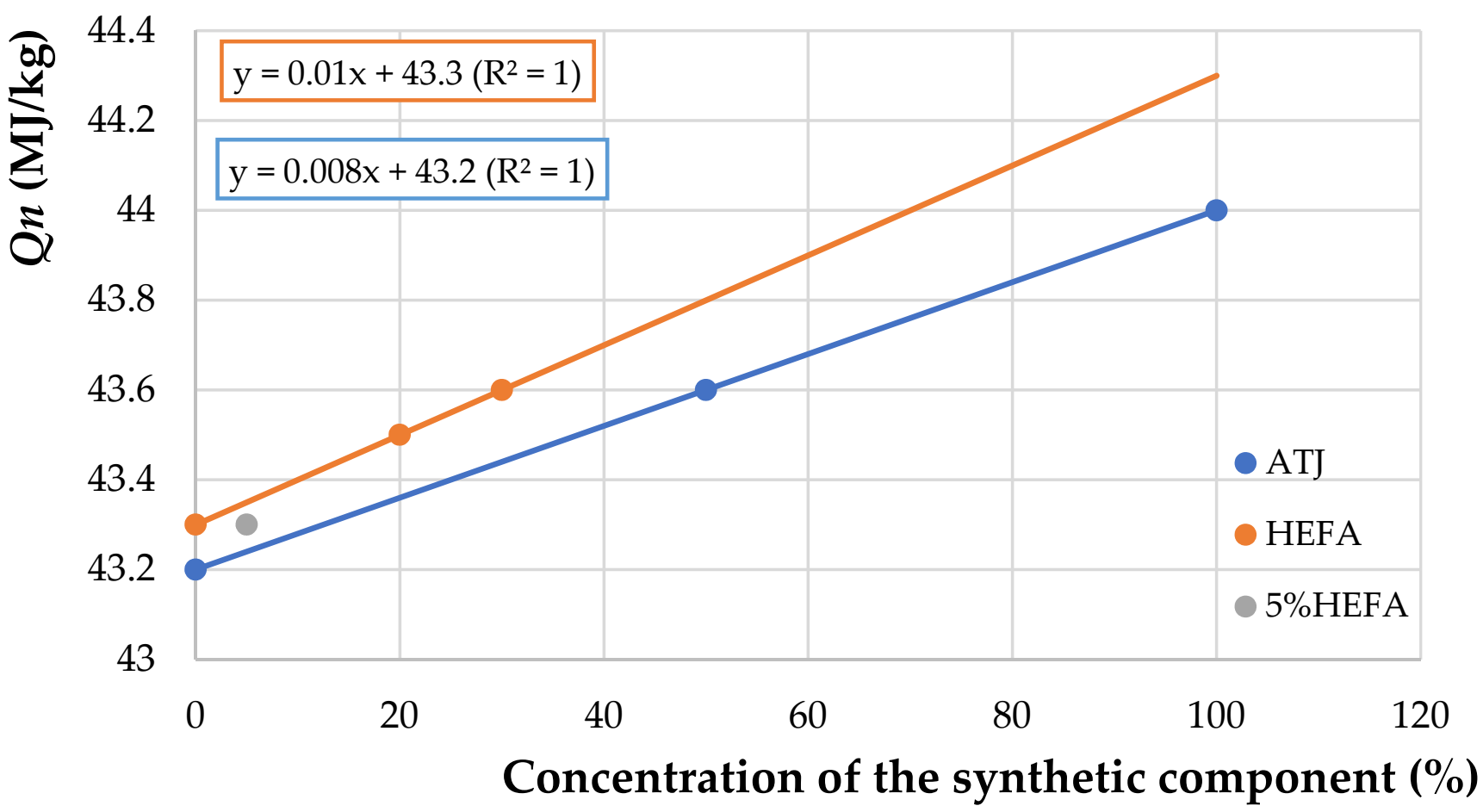

Figure 7. The relationship between calorific value $Q_{n}$ of the tested blends and the concentration of a synthetic component; properties of the blend containing 5\% of HEFA differ from the relationship found for blends containing HEFA in higher concentration.

Consequently, it can be concluded that the influence of synthetic components on the mechanism of the fuel combustion process is different in the case of blends containing HEFA component and blends containing ATJ. The above demonstrates the usefulness of the reac- 
tivity model in researching complex processes such as fuel combustion. Using the reactivity model, each parameter of obtained relationships can be interpreted physically/chemically. In contrast, other currently applied models are based on statistical dependences with all the recognized consequences, the most important being that statistically obtained parameters cannot be interpret physically/chemically.

\section{Conclusions}

In this paper, the application of the reactivity model developed in earlier research for comparing fuel combustion processes in turbine engines fueled by various synthetic blends was investigated. The analysis of the combustion process was carried out by means of a test rig with miniature turbojet engine. Conventional jet fuel and its blends with synthetic blending components derived from ATJ and HEFA technology were used in the bench tests.

The experimental data obtained allowed to develop trend lines described by power functions of the concentration of $\mathrm{CO}$ as dependent variable, and the fuel mass flow rate, $m_{f}$ as independent variable. For each of the tested blends, a power function was obtained with a different value of parameter $a$ and exponent $n$. Similar power functions can be formulated using the general reactivity model. While the parameters of the trend line cannot be physically interpreted, the quantities occurring in the relationships formulated on the basis of the reactivity model have a physical meaning. Consequently, the general reactivity model can be used to study the similarities and differences of various combustion mechanisms.

For each fuel chemical composition, a specific function was obtained, i.e., that the values of $a$ and $n$ parameters depend on the fuel chemical composition. Hence, it can be concluded that the $a$ parameter can be expressed as the function of net heat of combustion of the tested fuel and that the $Q_{n}$ varies linearly with the change of synthetic components concentration in the fuel.

The analysis of the relationship between $a$ values in power functions and the net heat of combustion of the tested blends leads to conclusion that there is different mechanism of combustion in cases wherein the fuel is the blend of Jet A-1 and HEFA and wherein the fuel contains a ATJ synthetic component.

The above conclusions require confirmation by increasing of the number of tested fuels. In the authors' opinion, Equations (19) and (28) will be useful in further planned research, including:

- $\quad$ Connection of $a$ and $n$ parameters with the physicochemical properties of tested fuels;

- $\quad$ Connection of $a$ and $n$ parameters with a wider group of engines.

Author Contributions: Conceptualization, A.K.; methodology, A.K. and T.B.; formal analysis, W.D.; investigation, T.B. and W.D.; writing-original draft preparation, A.K.; writing-review and editing, T.B. and M.K.; visualization, W.D. and A.K.; supervision, M.K. and A.K. All authors have read and agreed to the published version of the manuscript.

Funding: This research was funded by the Ministry of Science and Higher Education (Poland) for the project financed within the framework of the statutory activity.

Institutional Review Board Statement: Not applicable.

Informed Consent Statement: Not applicable.

Data Availability Statement: The data presented in this study are available on request from the corresponding author.

Conflicts of Interest: The author declares no conflict of interest. 


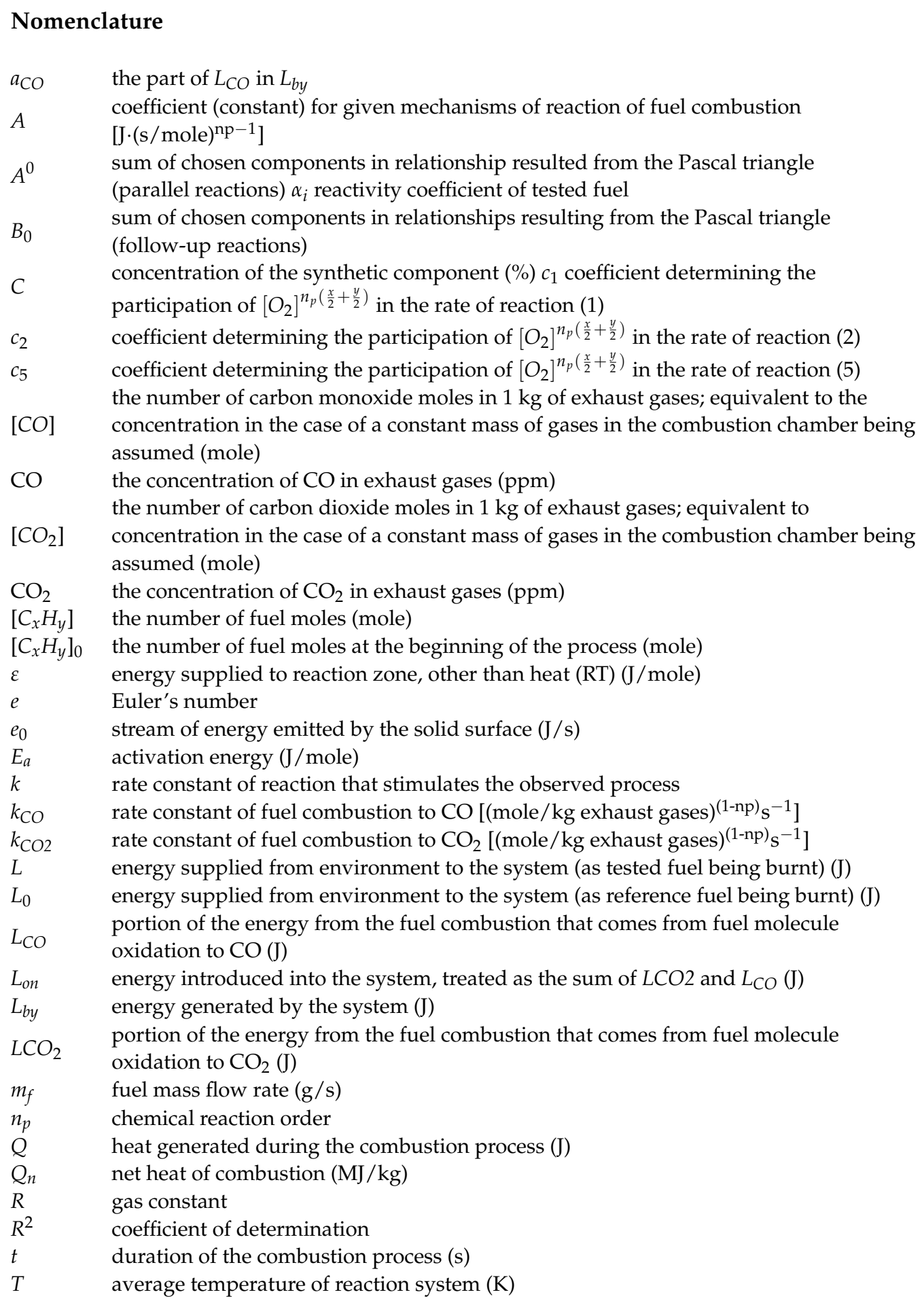

\section{References}

1. Directive (EU) 2018/2001 of the European Parliament and of the Council of 11 December 2018 on the Promotion of the Use of Energy from Renewable Sources. Available online: https:/ / eur-lex.europa.eu/legal-content/EN/TXT/?uri=CELEX\%3A32018L2 001 (accessed on 16 December 2020).

2. Navas-Anguita, Z.; García-Gusano, D.; Iribarren, D. Long-term production technology mix of alternative fuels for road transport: A focus on Spain. Energ. Convers. Manag. 2020, 226, 113498. [CrossRef]

3. Paulauskiene, T.; Bucas, M.; Laukinaite, M. Alternative fuels for marine applications: Biomethanol-biodiesel-diesel blends. Fuel 2019, 248, 161-167. [CrossRef]

4. Kumal, R.R.; Liu, J.; Gharpure, A.; Vander Wal, R.L.; Kinsey, J.S.; Giannelli, B.; Stevens, J.; Leggett, C.; Howard, R.; Forde, M.; et al. Impact of biofuel blends on black carbon emissions from a gas turbine engine. Energ. Fuel 2020, 34, 4958-4966. [CrossRef] 
5. Yang, J.; Xin, Z.; He, Q.; Corscadden, K.; Niu, H. An overview on performance characteristics of bio-jet fuels. Fuel 2019, 237, 916-936. [CrossRef]

6. ASTM International. ASTM D7566 Standard Specification for Aviation Turbine Fuel Containing Synthesized Hydrocarbons; ASTM International: West Conshohocken, PA, USA, 2020.

7. Zhang, B.Y.; Duan, D.; Hei, H.; Villota, E.; Ruan, R. Jet fuel production from waste plastics via catalytic pyrolysis with activated carbons. Appl. Energy 2019, 251, 113337. [CrossRef]

8. Kulczycki, A.; Kaźmierczak, U. Method of preliminary evaluation of bio components influence on the process of biofuels combustion in aviation turbine engines. J. KONES 2017, 24, 83-90.

9. Gawron, B.; Białecki, T.; Janicka, A.; Górniak, A.; Zawiślak, M. Exhaust toxicity evaluation in a gas turbine engine fueled by aviation fuel containing synthesized hydrocarbons. Aircr. Eng. Aerosp. Tec. 2020, 92, 60-66. [CrossRef]

10. Reksowardojo, I.K.; Duong, L.H.; Zain, R.; Hartono, F.; Marno, S.; Rustyawan, W.; Putri, N.; Jatiwiramurti, W.; Prabowo, B. Performance and exhaust emissions of a gas-turbine engine fueled with biojet/Jet A-1 blends for the development of aviation biofuel in tropical regions. Energies 2020, 13, 6570. [CrossRef]

11. Iturbe-Hernández, A.; Guzmán, J.E.V.; Vicente, W.; Salinas-Vazquez, M. Microturbine characteristics and emissions using biofuel blends. Biofuels 2020, 1-9. [CrossRef]

12. Przysowa, R.; Gawron, B.; Białecki, T.; Łegowik, A.; Merkisz, J.; Jasiński, R. Performance and emissions of a microturbine and turbofan powered by alternative fuels. Aerospace 2021, 8, 25. [CrossRef]

13. Karyeyen, S.; Ilbas, M. Experimental and numerical analysis of turbulent premixed combustion of low calorific value coal gases in a generated premixed burner. Fuel 2018, 220, 586-598. [CrossRef]

14. Pires, A.P.P.; Han, Y.; Kramlich, J.; Garcia-Perez, M. Chemical composition and fuel properties of alternative jet fules. BioResources 2018, 13, 2632-2657. [CrossRef]

15. Białecki, T.; Dzięgielewski, W.; Gawron, B.; Kaźmierczak, U.; Kulczycki, A. The role of molecularly ordered structures in energy transport enhancement during combustion process-A new conception of a reaction mechanism of fuel components oxidation. J. KONES 2018, 25, 17-24.

16. Jankowski, A.; Kowalski, M. Design of a new alloy for internal combustion engines pistons. In Proceedings of the 7th International Conference on Mechanics and Materials in Design (M2D2017), Albufeira, Portugal, 11-15 June 2017.

17. Żyluk, A.; Pietraszek, M. Investigation of an additional oxidizer charge effect onselected operational characteristics of a solidfuelrocket engine. J. Theor. Appl. Mech. 2014, 52, 139-149.

18. Dussan, K.; Won, S.H.; Ure, A.D.; Dryer, F.L.; Dooley, S. Chemical functional group descriptor for ignition propensity of large hydrocarbon liquid fuels. P. Combust. Inst. 2019, 37, 5083-5093. [CrossRef]

19. Anderson, A.; Karthikeyan, A.; Ramesh Kumar, C.; Ramachandran, S.; Praveenkumar, T.R. Lowest emission sustainable aviation biofuels as the potential replacement for the Jet-A fuels. Aircr. Eng. Aerosp. Tec. 2020, 93, 502-507.

20. Kozakiewicz, A.; Kowalski, M. Unstable operation of the turbine aircraft engine. J. Theor. Appl. Mech. 2013, 51, 719-727.

21. Kulczycki, A. Theoretical approach to modelling the combustion process in turbine engines fuelled by alternative aviation fuels containing various components / bio components. Combust. Engines 2017, 71, 245-249. [CrossRef]

22. Lefebvre, A.H.; Ballal, D.R. Gas Turbine Combustion: Alternative Fuels and Emissions, 3rd ed.; CRC Press: Boca Raton, FL, USA, 2010.

23. Gatchell, M.; Zettergren, H. Knockout driven reactions in complex molecules and their clusters. J. Phys. B At. Mol. Opt. 2016, 49, 1-19. [CrossRef]

24. Vanhpve, G.; Petit, G.; Minetti, R. Experimental study of the kinetic interactions in the low-temperature autoignition of hydrocarbon binary mixtures and a surrogate fuel. Combust. Flame 2006, 145, 521-532. [CrossRef]

25. Tanaka, S.; Ayala, F.; Keck, J.C.; Heywood, J.B. Two-stage ignition in HCCI combustion and HCCI control by fuels and additives. Combust. Flame 2003, 132, 219-239. [CrossRef]

26. ARP 1533C. Procedure for the Analysis and Evaluation of Gaseous Emission from Aircraft Engines; SAE International: Warrendale, PA, USA, 2016.

27. Govindan, R.; Jakhar, O.; Mathur, Y. Computational analysis of Thumba biodiesel-diesel blends combustion in CI engine using Ansys-fluent. IJCMS 2014, 3, 29-39.

28. Meeks, E.; Ando, H.; Choul, C.P.; Dean, A.M.; Hodgson, D.; Koshi, M.; Lengyel, I.; Maas, U.; Naik, C.V.; Puduppakkam, K.V.; et al. New modelling approaches using detailed kinetics for advanced engines. In Proceedings of the 9th International Conference on Modelling and Diagnostics for Advanced Engine Systems (COMODIA 2008), Sapporo, Japan, 28-31 July 2008.

29. Pitz, W.J.; Cernansky, N.P.; Dryer, F.L.; Egolfopulos, F.N.; Farrell, J.T.; Friend, D.G.; Pitsch, H. Development of an experimental database and chemical kinetic models for surrogate gasoline fuels. SAE Tech. Pap. 2007. [CrossRef]

30. Kajdas, C.; Kulczycki, A.; Ozimina, D. A new concept of the mechanism of tribocatalytic reactions induced by mechanical forces. Tribol. Int. 2017, 107, 144-151. [CrossRef]

31. Gawron, B.; Białecki, T. Impact of a Jet A-1/HEFA blend on the performance and emission characteristics of a miniature turbojet engine. Int. J. Environ. Sci. Technol. 2018, 15, 1501-1508. [CrossRef]

32. Gawron, B.; Białecki, T.; Janicka, A.; Suchocki, T. Combustion and emissions characteristics of the turbine engine fueled with HEFA blends from different feedstocks. Energies 2020, 13, 1277. [CrossRef] 
33. Suchocki, T.; Witanowski, Ł.; Lampart, P.; Kazimierski, P.; Januszewicz, K.; Gawron, B. Experimental investigation of performance and emission characteristics of a miniature gas turbine supplied by blends of kerosene and waste tyre pyrolysis oil. Energy 2021, 215, 119125. [CrossRef]

34. Gawron, B.; Białecki, T.; Górniak, A.; Janicka, A.; Zawiślak, M. An Innovative method for exhaust gases toxicity evaluation in the miniature turbojet engine. Aircr. Eng. Aerosp. Technol. 2017, 89, 757-763. [CrossRef]

35. Janicka, A.; Zawiślak, M.; Zaczyńska, E.; Czarny, A.; Górniak, A.; Gawron, B.; Białecki, T. Exhaust toxicity investigation of turbojet engine fed with conventional and biofuel, performed with aid of BAT-CELL Method. Toxicol. Lett. 2017, 280, 202. [CrossRef] 